\title{
Induction of Metabolic Hypofunction and Neurochemical Deficits after Chronic Intermittent Exposure to Phencyclidine: Differential Modulation by Antipsychotic Drugs
}

\author{
Susan M Cochran*,1, Matthew Kennedy',4, Clare E McKerchar', Lucinda J Steward ${ }^{1,5}$, Judith A Pratt ${ }^{1,2}$ and \\ Brian J Morris ${ }^{1,3}$ \\ 'Yoshitomi Research Institute of Neuroscience in Glasgow (YRING), University of Glasgow, UK; ${ }^{2}$ Department of Physiology and Pharmacology, \\ Strathclyde Institute for Biomedical Sciences, University of Strathclyde, Glasgow, UK; ${ }^{3}$ Institute of Biomedical and Life Sciences, University of \\ Glasgow, UK
}

\begin{abstract}
Numerous human imaging studies have revealed an absolute or relative metabolic hypofunction within the prefrontal cortex, thalamus and temporal lobes of schizophrenic patients. The former deficit correlates with cognitive deficits and negative symptoms, whereas the latter correlates with positive symptomologies. There is also general consensus that schizophrenia is associated with decreased parvalbumin expression in the prefrontal cortex. Since the drug phencyclidine can induce a psychosis resembling schizophrenia in humans, we have examined whether repeated phencyclidine (PCP) treatment to rats could produce similar metabolic and neurochemical deficits to those occurring in schizophrenia and whether these deficits could be modulated by antipsychotic drugs. We demonstrate here that chronic intermittent exposure to PCP $\left(2.58 \mathrm{mg} \mathrm{kg}^{-1}\right.$ i.p. $)$ elicits a metabolic hypofunction, as demonstrated by reductions in the rates of glucose utilization, within the prefrontal cortex, reticular nucleus of thalamus and auditory system, key structures displaying similar changes in schizophrenia. Moreover, chronic PCP treatment according to this regime also decreases parvalbumin mRNA expression in the rat prefrontal cortex and reticular nucleus of the thalamus. Chronic coadministration of haloperidol $\left(1 \mathrm{mg} \mathrm{kg}^{-1} \mathrm{day}^{-1}\right)$ or clozapine $\left(20 \mathrm{mg} \mathrm{kg}^{-1}\right.$ day $\left.^{-1}\right)$ with PCP did not modulate PCP-induced reductions in metabolic activity in the rat prefrontal cortex, but reversed deficits in the structures of the auditory system. Clozapine, but not haloperidol, reversed PCP-induced decreases in parvalbumin expression in prefrontal cortex GABAergic interneurons, whereas both drugs reversed the deficits in the reticular nucleus of the thalamus. These data provide important new information, which strengthen the validity of chronic PCP as a useful animal model of schizophrenia, when administered according to this protocol. Furthermore, we propose that reversal of PCP-induced reductions in parvalbumin expression in the prefrontal cortex may be a potential marker of atypical antipsychotic activity in relation to amelioration of cognitive deficits and negative symptoms of schizophrenia.
\end{abstract}

Neuropsychopharmacology (2003) 28, 265-275. doi:I0.1038/sj.npp. I30003।

Keywords: NMDA receptor antagonist; glucose utilization; thalamus; prefrontal cortex; schizophrenia; parvalbumin

\section{INTRODUCTION}

The use of phencyclidine (PCP) as an animal model of schizophrenia has received much attention over the past few years. PCP and its congener, ketamine, have been shown to induce a psychosis in humans that closely resembles

* Correspondence: Dr S Cochran, Yoshitomi Research Institute of Neuroscience in Glasgow (YRING), University of Glasgow, GI2 8QQ, UK, Tel: +44 I4I 330 5153, Fax: +44 I4I 3305659 , E-mail: yring@bio.gla.ac.uk

${ }^{4}$ Present address: Department of Pharmacology, Division of Neuroscience, University of Birmingham, Edgbaston, Birmingham, BI5 2TT, UK.

${ }^{5}$ Present address: Hoffman-La Roche Ltd, Grenzacher Strasse, $\mathrm{CH}$ 4070 Basel, Switzerland.

Received 28 February 2002; revised I July 2002; accepted 8 July 2002 schizophrenia and is representative of both the negative and positive symptoms of the disease, and also to exacerbate symptoms in chronic stabilized schizophrenic patients (Luby et al, 1959; Allen and Young, 1978; Javitt and Zukin, 1991; Krystal et al, 1994). Animal studies have demonstrated that acute treatment with PCP gives rise to an array of symptoms that relate to schizophrenia, including cognitive deficits (Adams and Moghaddam, 1998; Kesner and Dakis, 1997; Jentsch et al, 1997a,b), disruption in sensory motor gating (Mansbach and Geyer, 1989) and impaired social interaction (Sams-Dodd, 1997). Furthermore, it has been demonstrated that some effects of NMDA receptor antagonists (such as neurotoxicity) in rats are agedependent (Farber et al, 1995; Olney and Farber, 1995), which reflects a similar scenario in humans in relation to the onset of sensitivity to the psychotomimetic effects of 
ketamine (Reich and Silvay, 1989) and the symptoms of schizophrenia. Subchronic exposure to PCP produces a persistent decrease in dopamine utilization within the prefrontal cortex, which is accompanied by a deficit in working memory in prefrontal cortex-dependent tasks in both rats (Jentsch et al, 1997a) and nonhuman primates (Jentsch et al, 1997b). These findings have been reviewed by Jentsch and Roth (1999) as supporting NMDA receptor antagonist models of schizophrenia.

Numerous human imaging studies have employed positron emission tomography in schizophrenic patients, either to measure cerebral blood flow or else to measure local cerebral glucose utilization, which is directly related to neuronal activity, with $\left[{ }^{18} \mathrm{~F}\right]$ fluorodeoxyglucose (FDGPET). These studies have frequently revealed an absolute or relative metabolic hypofunction within particular brain areas that have been shown to have altered neuropathology and neurochemical deficits in schizophrenia (Hazlett et al, 2000; Buchsbaum and Hazlett, 1998; Cohen et al, 1997; Buchsbaum et al, 1996; Nordahl et al, 1996; Schroder et al, 1996, 1994; Potkin et al, 1994; Wolkin et al, 1992; Andreasen et al, 1992; Tamminga et al, 1992; Buchsbaum et al, 1990). In particular, the altered metabolic activity in the prefrontal cortex in the schizophrenic brain has been shown to correlate with the presence and severity of negative symptoms and cognitive deficits (Hazlett et al, 2000; Volz et al, 1999; Buchsbaum and Hazlett, 1998; Schroder et al, 1996; Schroeder et al, 1994; Wolkin et al, 1992; Tamminga et al, 1992; Andreasen et al, 1992; Buchsbaum et al, 1990), while altered metabolic activities within the temporal lobe and thalamus have been shown to correlate with positive symptomology (Buchsbaum and Hazlett, 1998; Buchsbaum et al, 1996; Nordahl et al, 1996; Schroder et al, 1996; Tamminga et al, 1992).

Moreover, chronic exposure to PCP in humans has been shown to produce a metabolic hypofunction during frontal activation tasks (Wu et al, 1991), similar to that observed in schizophrenia, and to produce enduring cognitive deficits (Cosgrove and Newell, 1991). Strikingly, however, chronic PCP treatment has never been shown to produce a neuroanatomical pattern of hypofunction in rodents, which mirrors that observed in schizophrenic patients. We tested the hypothesis that repeated exposure of PCP to rats would produce a metabolic hypofunction in structures of the brain associated with this phenomenon in schizophrenia. We used the technique of quantitative ${ }^{14} \mathrm{C}$-2-deoxyglucose autoradiography (Sokoloff et al, 1977), akin to that of FDG-PET used in humans (Phelps et al, 1979), to measure the effect of chronic intermittent exposure to PCP on local cerebral glucose utilization (LCGU) in rats. Chronic intermittent administration of PCP was chosen so that chronic administration of antipsychotic drugs could be incorporated into the regime, to represent the fact that in humans the full therapeutic potential of antipsychotics may be delayed for 2-3 weeks (Freed, 1988). In order to evaluate the effect of chronic antipsychotic treatment on PCPinduced alterations in LCGU, the effect of subchronic and intermittent chronic exposure to PCP was first determined so as to establish whether an altered metabolic state existed before and after the intended duration of antipsychotic therapy. The effect of chronic antipsychotic treatment on the altered metabolic state induced by chronic intermittent exposure to PCP was then assessed. The effect of chronic PCP treatment on a particular neurochemical marker, parvalbumin, that has also been shown to be altered in post-mortem tissue from schizophrenic brains (Lewis, 2000; Pierri et al, 1999; Ohnuma et al, 1999; Danos et al, 1998) was also investigated within certain brain structures that have altered metabolic activity or pathophysiology in schizophrenia.

\section{METHODS}

\section{Animals}

Male hooded Long Evans rats (Harlan-Olac, UK), weighing $180-220 \mathrm{~g}$ at the beginning of treatment, were housed under a $12 \mathrm{~h}$ light/dark cycle in a temperature- and humiditycontrolled environment with free access to food and water. Animals were handled for a few minutes daily, 1 week prior to the start of injections. All animal experiments were carried out in accordance with the UK Animals (Scientific Procedures) Act, 1986 and associated guidelines.

\section{Drugs}

Phencyclidine hydrochloride (PCP) was obtained from Sigma-Aldrich (UK) and was dissolved in saline. Haloperidol hydrochloride was obtained from Research Biochemicals Inc. (USA) and clozapine was synthesized by Welfide Corporation, Japan and were dissolved in 3\% glacial acetic acid in $\mathrm{H}_{2} \mathrm{O}(\mathrm{pH}$ 5). Doses of PCP and haloperidol are expressed as salt equivalent and as base for clozapine.

\section{Treatment Regimes}

Subchronic PCP exposure: i.p. injections of PCP $\left(0.86 \mathrm{mg} \mathrm{kg}^{-1}\right.$ or $\left.2.58 \mathrm{mg} \mathrm{kg}^{-1}\right)$ or saline $\left(1 \mathrm{ml} \mathrm{kg}^{-1}\right)$ once daily for 5 days.

Chronic intermittent PCP exposure: i.p. injections of PCP $\left(0.86 \mathrm{mg} \mathrm{kg}^{-1}\right.$ or $\left.2.58 \mathrm{mg} \mathrm{kg}^{-1}\right)$ or saline $\left(1 \mathrm{ml} \mathrm{kg}^{-1}\right)$ once daily on days $1-5,8,10,12,15,17,19,22,24,26$.

Combined chronic intermittent PCP exposure and antipsychotic treatment: i.p. injections of PCP $\left(2.58 \mathrm{mg} \mathrm{kg}^{-1}\right)$ or saline $\left(1 \mathrm{ml} \mathrm{kg}^{-1}\right)$ once daily on days $1-5,8,10,12,15,17$, $19,22,24,26$. Osmotic minipumps (2ML4 (28 days), Alzet) were implanted subcutaneously on day 8 prior to PCP injection to deliver doses of $20 \mathrm{mg} \mathrm{kg}^{-1} \mathrm{day}^{-1}$ clozapine, $1 \mathrm{mg} \mathrm{kg}^{-1}$ day $^{-1}$ haloperidol or vehicle ( $3 \%$ glacial acetic acid in $\mathrm{H}_{2} \mathrm{O}$ ). The osmotic minipumps were primed in vitro for $24 \mathrm{~h}$ in order to ensure pumping started immediately upon implantation.

\section{Quantitative 2-Deoxyglucose Autoradiography}

Seventy-two hours after the last exposure to PCP (subchronic, day 8 and chronic intermittent, day 29), the animals were surgically prepared according to the adaptation of the original technique for freely moving rats (Crane and Porrino, 1989). Briefly, the animals were anaesthetized with halothane, and polyethylene cannulae $(45 \mathrm{~cm})$ were subcutaneously tunneled from the nape of the neck to the groin. The femoral artery and vein were then isolated and cannulated, with the cannulae secured in place with silk ties. 
A local anaesthetic was applied to the groin (1\% Xylocaine Gel, AstraZeneca) and the subcutaneous tunnel (2\% Xylocaine Injection, AstraZeneca) before suturing. The animal was then placed in its home cage under temperature-controlled conditions to recover. The animals' blood pressure, blood gases and rectal temperature were measured intermittently during the 2 -h recovery period and experimental period.

The experimental procedure was initiated by a bolus intravenous injection of ${ }^{14} \mathrm{C}$-2-deoxyglucose $\left({ }^{14} \mathrm{C}\right.$-2-DG, New England Nuclear, USA). Simultaneously, arterial blood samples $(50-100 \mu \mathrm{l})$ were collected at timed intervals $(0,15$, $30,45 \mathrm{~s}, 1,2,5,7.5,10,15,25,35,45$ minutes). The experiment was terminated after $45 \mathrm{~min}$ with an intravenous dose of sodium pentobarbitone (Sagital, Rhone Merieux). The brain was quickly removed and frozen. Plasma was prepared from the arterial blood samples and was used to measure plasma glucose levels (Glucose II Analyzer, Beckman) and plasma ${ }^{14} \mathrm{C}$ concentrations ( $\beta$-scintillation counting, Packard) at each time point. The brains were sectioned at $-20^{\circ} \mathrm{C}$ in a cryostat (CM1850, Leica), with $20 \mu \mathrm{m}$ sections collected in triplicate every $200 \mu \mathrm{m}$ throughout the brain. The sections were quickly dried at $60^{\circ} \mathrm{C}$ and exposed to Xray film (Biomax MR, Kodak) with previously calibrated ${ }^{14} \mathrm{C}$-methylmethacrylate standards (Amersham) for 4 days. The films were analyzed using computer-based densitometry (MCID 5, Canada) and the ${ }^{14} \mathrm{C}$ tissue concentrations measured from discrete brain structures coupled with the animals plasma glucose, and ${ }^{14} \mathrm{C}$ concentrations were then used to calculate (LCGU) using the operational equation derived by Sokoloff et al (1977). LCGU was determined in some 50 discrete brain structures. For each structure, readings were taken from three consecutive sections, with the mean of these readings being taken as the value for each animal. The mean values from each animal were then combined to give a mean treatment group value, as is standard for autoradiographical analysis. Anatomical delineation was carried out by an experienced researcher guided by the rat brain atlas of Paxinos and Watson (1998). Similarly, delineation of layers of the cortex was carried out by a researcher with considerable experience in comparing consecutive stained sections (cresyl violet/luxol fast blue) with the autoradiograph images. Osmotic minipumps, when used, were removed at the end of the experiment in order to verify that the correct dose had been delivered.

\section{In situ Hybridization}

Animals were killed by cervical dislocation $72 \mathrm{~h}$ after the last exposure to PCP or saline (day 29) and the brains were quickly removed and frozen. Sections $20 \mu \mathrm{m}$ thick were collected onto poly L-lysine-coated slides from the following four bregma levels according to Paxinos and Watson (1998): $3.2 \mathrm{~mm}$ (prelimbic cortex); $1.6 \mathrm{~mm}$ (anterior cingulate cortex); $-1.80 \mathrm{~mm}$ (reticular nucleus of the thalamus); $-4.80 \mathrm{~mm}$ (dentate gyrus, hippocampus and auditory cortex). These levels were selected on the basis of preliminary experiments that showed measurable levels of parvalbumin mRNA expression in discrete brain structures at these levels. Sections were dried at room temperature, then fixed in freshly prepared $4 \%$ (wt/vol) paraformaldehyde in phosphate-buffered saline (PBS) for $5 \mathrm{~min}$. After rinsing, the sections were sequentially dehydrated in $70 \%$, $95 \%$ and $100 \%$ ethanol before being stored under ethanol at $4{ }^{\circ} \mathrm{C}$.

A 45mer oligonucleotide probe (Cruachem Ltd, UK) was designed against bases 223-267 of the rat parvalbumin gene (GenBank accession number AA819345). The probe was $3^{\prime}$ end-labeled with terminal deoxyribonucleotidyl transferase (Boehringer Mannheim) and with the isotope $5-\alpha-{ }^{35}$ S-dATP (NEN, specific activity $>1000 \mathrm{Ci} / \mathrm{mmol}$ ) and incubated at $37^{\circ} \mathrm{C}$ for $1 \mathrm{~h}$. The reaction was terminated by addition of $40 \mu \mathrm{l}$ diethyl pyrocarbonate (DEPC)-treated water. The labeled probe was purified using QiaQuick Columns (Qiagen). The extent of probe labeling was assessed using $\beta$-scintillation counting. Sections were hybridized overnight at $42^{\circ} \mathrm{C}$ in a hybridization mixture comprising hybridization buffer (50\% deionized formamide, $20 \% 20 \times$ standard saline citrate $(20 \times \mathrm{SSC}=3 \mathrm{M}$ sodium chloride; $0.3 \mathrm{M}$ sodium citrate, $\mathrm{pH} 7), 5 \% 0.5 \mathrm{M}$ sodium phosphate $(\mathrm{pH} 7), 1 \%$ $0.1 \mathrm{M}$ sodium pyrophosphate, $2 \% 5 \mathrm{mg} \mathrm{ml}^{-1}$ polyadenylic acid, $10 \%$ dextran sulfate, volume adjusted to $50 \mathrm{ml}$ with DEPC-treated water), $5 \mathrm{ng} 5000 \mu \mathrm{l}^{-1}$ labeled probe and $1 \mathrm{M}$ DTT in the proportion 100:2:4. A total of $200 \mu \mathrm{l}$ of hybridization mixture was applied to each slide and the sections were then covered with parafilm. After overnight hybridization under humidified conditions, the parafilm was removed from each slide under $1 \times$ SSC and washed for $30 \mathrm{~min}$ in $1 \times \mathrm{SSC}$ at $60^{\circ} \mathrm{C}$. The sections were then washed in $1 \times$ SSC followed by $0.1 \times$ SSC at room temperature and dehydrated in $70 \%, 95 \%$ then $100 \%$ ethanol. Once dry, then sections were exposed to autoradiographic film (Biomax MR, Kodak) for 5 days. Autoradiograms were analyzed using the MCID densitometry system. Osmotic minipumps, when used, were removed at the end of the experiment in order to verify that the correct dose had been delivered.

After exposure to X-ray film, nuclear emulsion staining of the parvalbumin-labeled section was carried out. Sections were exposed to photographic emulsion for 20 days at 2$8{ }^{\circ} \mathrm{C}$. After development and fixation, the sections were counter stained with neutral red. The sections were then analyzed under a microscope and the numbers of cells showing silver grain counts above background levels were counted ( $\times 10$ magnification) within the prelimbic region of the prefrontal cortex. The density of cellular silver grains ( $x 40$ magnification) was also measured within the prelimbic region of the prefrontal cortex and the reticular nucleus of the thalamus (MCID imaging system).

\section{Statistics}

In the initial exploratory study, in order to identify brain structures showing altered functional activity after PCP treatment, LCGU data (two doses of PCP $v s$ vehicle) after subchronic (day 8) and chronic intermittent treatment (day 29) were separately analyzed using an individual one-way ANOVA for each discrete brain structure, with significance taken as $p<0.05$ after correction for multiple comparisons using the sequential Bonferroni method. This was followed, when significant, by Dunnett's post hoc test. Post hoc significance was defined as $p<0.05$.

In the second study, to assess the ability of concurrent antipsychotic administration to modulate altered functional activity induced by chronic intermittent PCP $\left(2.58 \mathrm{mg} \mathrm{kg}^{-1}\right)$ 
treatment in the brain structures identified in the first exploratory study, data were analyzed initially by a repeated measures ANOVA (factors: brain structure and treatment). If a significant interaction between brain structure and treatment occurred, the following separate analyses were carried out: (1) $t$-test (vehicle-vehicle $v s$ PCP-vehicle), with significance taken as $p<0.05$ to verify PCP-induced altered glucose utilization in each brain structure; (2) one-way ANOVA (PCP-vehicle vs PCP-clozapine and PCP-haloperidol), with significance taken as $p<0.05$ after correction for multiple comparisons using the sequential Bonferroni method, followed where appropriate by Tukey's post hoc test (post hoc significance taken as $p<0.05$ ), to determine whether chronic antipsychotic treatment could reverse the PCP-induced effect and (3) one-way ANOVA (vehiclevehicle $v s$ vehicle-clozapine and vehicle-haloperidol), with significance taken as $p<0.05$ after correction for multiple comparisons using the sequential Bonferroni method, followed where appropriate by Tukey's post hoc test (post hoc significance taken as $p<0.05$ ), to determine whether chronic antipsychotic treatment produced an effect on its own).

In situ hybridization results were statistically analyzed using individual one-way ANOVA for each discrete brain structure, corrected for multiple comparisons using the sequential Bonferroni correction method (significance taken as $p<0.05$ after correction for multiple comparisons), followed by Tukey's post hoc test where appropriate (post hoc significance taken as $p<0.05$ ).

\section{RESULTS}

\section{Effect of Subchronic and Chronic Intermittent Exposure to PCP on LCGU}

The effect of two doses of PCP was assessed: $0.86 \mathrm{mg} \mathrm{kg}^{-1}$, which is reportedly selective for the NMDA channel; and $2.58 \mathrm{mg} \mathrm{kg}^{-1}$, a dose which is three-fold higher but less than the $\mathrm{ED}_{50}$ for PCP-induced cell death (Olney et al, 1989). LCGU was measured $72 \mathrm{~h}$ after the last exposure to PCP, so the results were independent of the acute effects of the drug.

Subchronic and chronic intermittent PCP treatment revealed regionally selective changes in LCGU in 10 of the 50 structures examined. These changes were in structures shown to be important in the pathophysiology of schizophrenia (Table 1). The dose of $2.58 \mathrm{mg} \mathrm{kg}^{-1}$ PCP induced a regionally specific metabolic hypofunction in these structures that was evident after both subchronic (day 8) and chronic intermittent treatment (day 29). Significant changes in LCGU occurred within prefrontal cortical structures (Uylings and van Eden, 1990; Paxinos, 1995; Ongur and Price, 2000) such as layers V and VI of the medial orbital cortex $(-18$ to $-28 \%)$ and all layers of the prelimbic cortex $(-14$ to $-24 \%)$. There were also significant changes in LCGU within subcortical structures of the auditory system (the dorsal and lateral lemniscus and the cochlear nucleus) $(-18$ to $-26 \%)$ and the reticular nucleus of the thalamus ( -25 to $-29 \%)$. Within the auditory cortex, a significant change (after correction for multiple corrections) was confined to layers II-IV of the secondary auditory cortex at day 29 after the dose of $2.58 \mathrm{mg} \mathrm{kg}^{-1}$.
The lower dose of PCP $\left(0.86 \mathrm{mg} \mathrm{kg}^{-1}\right)$ produced a virtually identical pattern of hypofunction as the $2.58 \mathrm{mg} \mathrm{kg}^{-1}$ dose of PCP after subchronic treatment (day 8). However, this was not evident within many of the structures after chronic intermittent treatment (day 29), suggesting that there is a threshold dose for maintaining the metabolic hypofunction with intermittent treatment. LCGU remained unaltered in the majority of the other structures investigated, such as in the hippocampus, anterior cingulate cortex, basal ganglia, anterior and midline thalamic nuclei and structures of the visual system (data not shown).

\section{Effect of Chronic Antipsychotic Administration on PCP-Induced Metabolic State}

A dose of $2.58 \mathrm{mg} \mathrm{kg}^{-1}$ PCP was used as the previous studies demonstrated that an altered metabolic state was apparent both before and after the intended duration of antipsychotic treatment. Administration of haloperidol $\left(1 \mathrm{mg} \mathrm{kg}^{-1}\right.$ day $\left.^{-1}\right)$ and clozapine $\left(20 \mathrm{mg} \mathrm{kg}^{-1} \mathrm{day}^{-1}\right)$ via osmotic minipumps has been shown in previous experiments within our laboratory to provide equivalent plasma concentrations of the drugs that were within therapeutic ranges (data not shown). As with the previous experiment, LCGU was measured $72 \mathrm{~h}$ after the last exposure to PCP or saline. Table 2 shows LCGU after chronic treatment with haloperidol and clozapine alone, and in conjunction with chronic intermittent PCP treatment in brain structures identified as having altered LCGU after chronic intermittent PCP treatment in the initial exploratory studies (see also Figure 1). Repeated measures ANOVA revealed a significant effect of brain structure $(\mathrm{F}(9,252)=121.35, p<0.001)$, treatment $(\mathrm{F}(5,28)=7.41, \quad p<0.001)$ and a significant interaction between treatment and brain structure $(\mathrm{F}(45,252)=1.83, p=0.002)$. As a significant interaction between brain structure and treatment was obtained, further analysis was carried out for each brain structure. A significant difference between vehicle-vehicle and PCPvehicle was observed within all structures analyzed, with the exception of the medial orbital cortex. This confirms the results of the initial exploratory study (except for the medial orbital cortex), where a metabolic hypofunction was observed in the prelimbic cortex, the reticular nucleus of the thalamus, the dorsal nucleus of the auditory cortex (layers II-IV), the lateral lemniscus (dorsal and ventral nuclei), and the cochlear nucleus. The ability of chronic antipsychotic treatment to reverse the PCP-induced effects was then investigated using a one-way ANOVA followed by Tukey's post hoc test. Within the lateral lemniscus (dorsal and ventral nuclei), and the cochlear nucleus only, a significant effect was observed. Post hoc analysis revealed that within the dorsal nucleus of the lateral lemniscus and the cochlear nucleus, chronic clozapine and chronic haloperidol in conjunction with chronic intermittent PCP treatment were significantly different from PCP-vehicle, although there was no significant difference between chronic clozapine and chronic haloperidol treatment. Within the ventral nucleus of the lateral lemniscus, only chronic clozapine treatment reversed the PCP-induced metabolic hypofunction. This shows that chronic antipsychotic treatment can reverse the PCP-induced effects in the lateral lemniscus and the cochlear nucleus, but not within 
Table I Induction and Maintenance of PCP-Induced Hypofunction

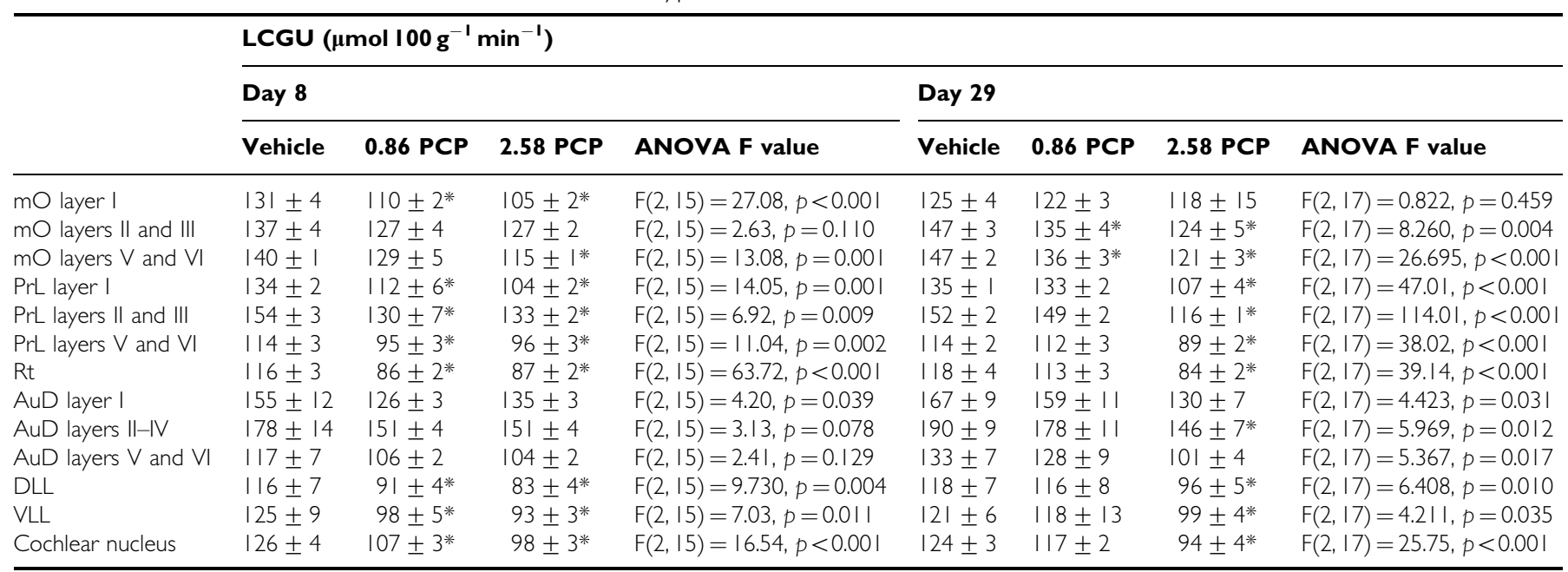

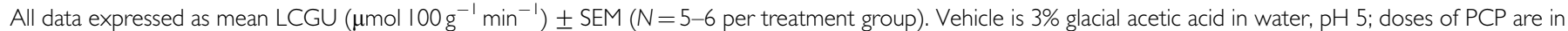
$\mathrm{mg} \mathrm{kg}^{-1}$. Data were analyzed by one-way ANOVA for each brain structure, corrected for multiple comparisons using the sequential Bonferonni correction method (significance taken as $p<0.05$ after correction for multiple comparisons; please note that the uncorrected $p$-values are shown in the table) followed, where appropriate, by Dunnett's post hoc test. $*$ p $<0.05$ compared to controls (post hoc analysis against vehicle-treated rats). Within AuD layer I (days 8 and 29) and AuD layers $\mathrm{V}$ and $\mathrm{VI}$ (day 29), after correction for multiple comparisons, $p>0.05$. Abbreviations: $\mathrm{mO}$, medial orbital cortex; PrL, prelimbic cortex; Rt reticular nucleus of the thalamus; Au, primary auditory cortex; AuD, dorsal nucleus of the secondary auditory cortex; DLL and VLL, dorsal nucleus and ventral nucleus of the lateral lemniscus.

Table 2 Effect of Haloperidol and Clozapine on PCP-Induced Hypofunction

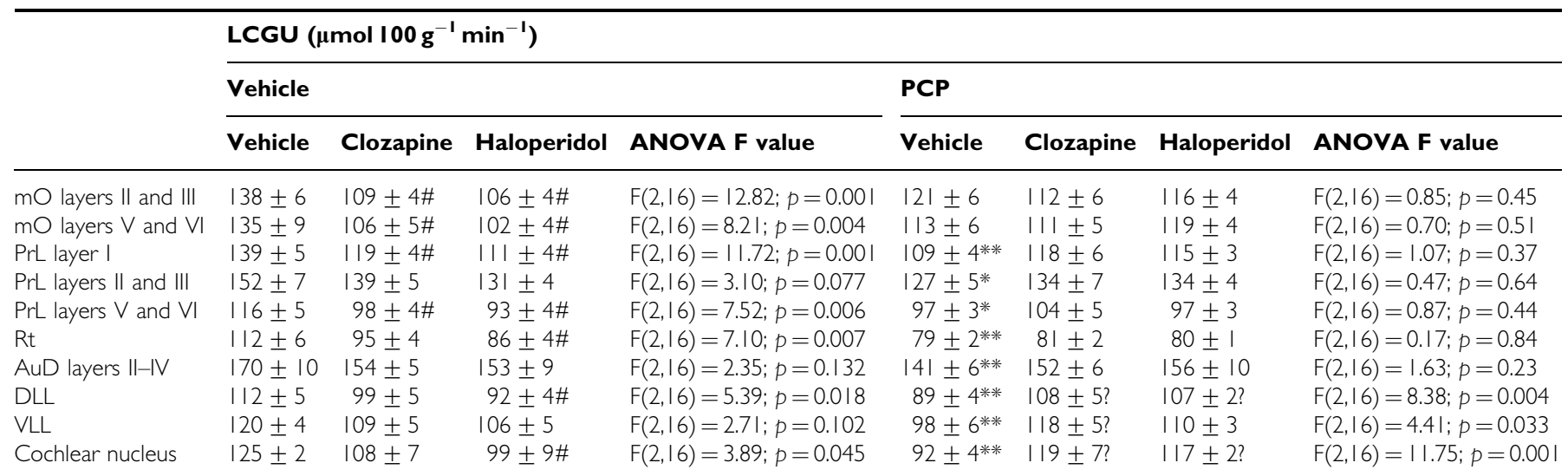

All data expressed as mean LCGU ( $\mu$ mol l $\left.00 \mathrm{~g}^{-1} \mathrm{~min}^{-1}\right) \pm \mathrm{SEM}(\mathrm{N}=6$ per treatment group). Vehicle is $3 \%$ glacial acetic acid in water, $\mathrm{pH} 5$; dose of PCP is $2.58 \mathrm{mg} \mathrm{kg}^{-1}$, according to the regime described in the Methods section; haloperidol dose $=1 \mathrm{mg} \mathrm{kg}^{-1}$ day $^{-1}$; clozapine dose $20 \mathrm{mg} \mathrm{kg}^{-1}$ day ${ }^{-1}$. Statistical analysis by repeated measures ANOVA (factors: brain structure and treatment) revealed a significant interaction between brain structure and treatment. This was then followed by t-test (vehicle-vehicle and PCP-vehicle) and one-way ANOVAs (PCP-vehicle and PCP-antipsychotics; vehicle-vehicle and vehicle-antipsychotics) in individual brain structures. After correction for multiple comparisons using the sequential Bonferroni method (one-way ANOVAs; please note the uncorrected $p$-value is shown in the table), the one-way ANOVA was followed where appropriate by the Tukey's post hoc test. $* p<0.05, * * * 0.00$ I PCP-vehicle compared to vehicle-vehicletreated animals (t-test). ? $<<0.05$ (post hoc analysis) PCP-antipsychotics compared to PCP-vehicle. \#p $<0.05$ (post hoc analysis) vehicle-antipsychotics compared to vehicle-vehicle-treated animals. Abbreviations are as in Table I legend.

other structures (prelimbic cortex, dorsal nucleus of the auditory cortex and the reticular nucleus of the thalamus). In order to determine whether the antipsychotics alone produced an effect on LCGU, a further one-way ANOVA was carried out. No significant effect of the antipsychotics alone was observed within the prelimbic cortex (layers II and III), the dorsal nucleus of the secondary auditory cortex and the ventral nucleus of the lateral lemniscus. Within the medial orbital cortex and the prelimbic cortex (layers I, V and VI), both chronic clozapine and haloperidol produced a significant decrease in LCGU. A significant effect was also observed within the reticular nucleus of the thalamus, dorsal nucleus of the lateral lemniscus and the cochlear nucleus. Within these three structures, only chronic haloperidol significantly decreased LCGU compared to vehicle-vehicle-treated rats. This suggests that clozapine and haloperidol may be acting via different mechanisms to reverse the effects of chronic intermittent PCP treatment, as clozapine did not have a significant effect on LCGU alone. 
Effect of Treatment Regime on Parvalbumin mRNA Expression

As for the LCGU experiments, in situ hybridization was carried out $72 \mathrm{~h}$ after the last exposure to PCP or saline. Parvalbumin mRNA expression was confined to particular

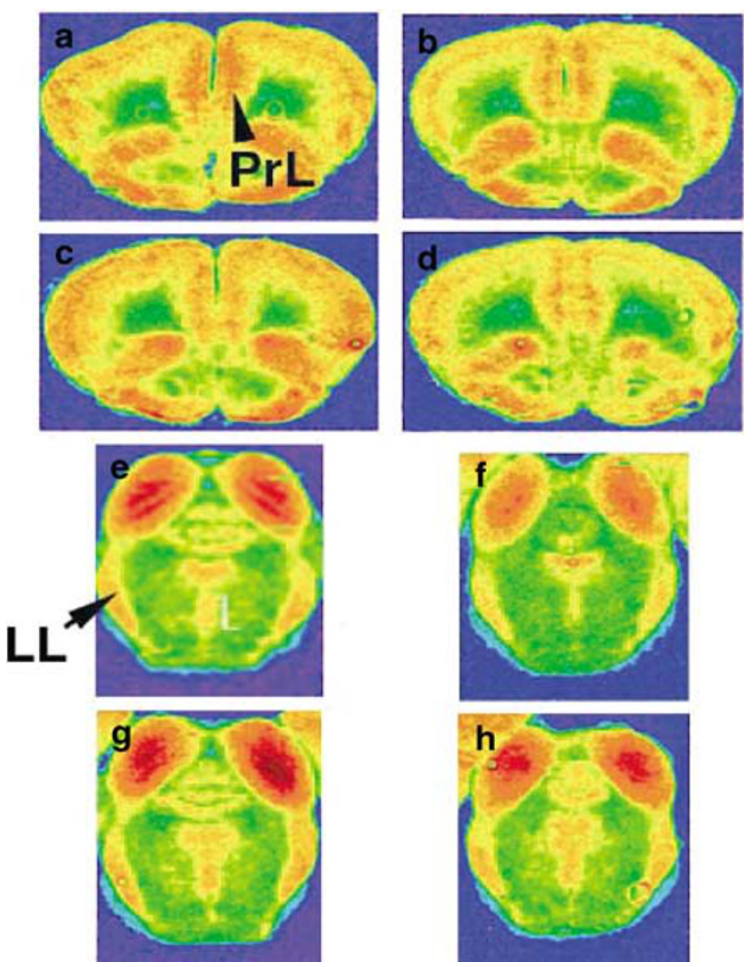

Figure I PCP-induced decreases in LCGU. (a-d) The prelimbic structure (PrL) of the prefrontal cortex and $(e-h)$ within the lateral lemniscus (LL) of the auditory system. (a,e) Vehicle-vehicle (control); ( $b, f)$ PCP-vehicle; (c,g) PCP-clozapine; (d,h) PCP-haloperidol. Note the lack of reversal of the $\mathrm{PCP}$-induced hypofunction within the prelimbic structure, but the reversal of the PCP-induced hypofunction by clozapine and haloperidol in conjunction with PCP within the lateral lemniscus. brain structures (Table 3). The one-way ANOVA revealed a significant effect of PCP treatment on parvalbumin mRNA within layers II, III, V and VI of the prelimbic cortex. The subsequent post hoc analysis showed that chronic PCP treatment produced a significant decrease in parvalbumin mRNA expression compared to vehicle-vehicle-treated animals $(-25$ to $-27 \%)$. This PCP-induced decrease in parvalbumin expression in the prelimbic cortex was reversed by clozapine but not by haloperidol (Table 3 ). The one-way ANOVA also revealed a significant effect of treatment on parvalbumin mRNA within the ventral reticular nucleus of the thalamus. The subsequent post hoc analysis revealed that chronic PCP treatment produced a significant decrease in parvalbumin mRNA expression compared to vehicle-vehicle-treated animals $(-22 \%)$ that was reversed by both clozapine and haloperidol (Table 3 ). After nuclear emulsion dipping, no difference was observed in the number of parvalbumin-labeled cells per unit area between treatment groups in the prelimbic region of the prefrontal cortex (Figure 2a). However, the density of cellular silver grains was significantly decreased by chronic PCP within the prelimbic cortex $(-25 \%$, Figures 2 and $3 \mathrm{~b})$ and within the ventral reticular nucleus of the thalamus $(-29 \%$, Figures $2 \mathrm{c}$ and 3$)$. Within the prelimbic cortex, the decreases were reversed by clozapine but not haloperidol (Figure 2b), whereas within the reticular nucleus of the thalamus, both clozapine and haloperidol reversed the PCPinduced decreases in parvalbumin mRNA expression (Figure 2c).

\section{DISCUSSION}

This is the first time that the chronic effects of PCP on LCGU in the rat have been reported. We have shown that chronic intermittent exposure to PCP produces a specific pattern of hypometabolism within the rat brain. A robust, reproducible metabolic hypofunction was observed within the prelimbic cortex, the reticular nucleus of the thalamus,

Table 3 Effect of PCP and Antipsychotic Drug Effects on Film Autoradiographic in situ Hybridization Signal for Parvalbumin mRNA Expression

\begin{tabular}{llllll}
\hline \multicolumn{7}{l}{ Relative optical density } \\
\cline { 2 - 6 } & Vehicle-vehicle & PCP-vehicle & PCP-clozapine & PCP-haloperidol & ANOVA F value \\
\hline PrL layers II and III & $0.072 \pm 0.001$ & $0.054 \pm 0.002^{*}$ & $0.069 \pm 0.005^{\dagger} \#$ & $0.056 \pm 0.002^{*}$ & $F(3,31)=9.53, p<0.001$ \\
PrL layers V and VI & $0.077 \pm 0.003$ & $0.056 \pm 0.003^{*}$ & $0.072 \pm 0.004^{\dagger} \#$ & $0.060 \pm 0.002^{*}$ & $F(3,31)=10.12, p<0.00 I$ \\
Acg & $0.124 \pm 0.005$ & $0.113 \pm 0.004$ & $0.125 \pm 0.003$ & $0.121 \pm 0.005$ & $F(3,31)=1.52, p=0.231$ \\
Aul & $0.105 \pm 0.006$ & $0.104 \pm 0.006$ & $0.109 \pm 0.004$ & $0.100 \pm 0.007$ & $F(3,31)=0.38, p=0.767$ \\
AuD & $0.108 \pm 0.009$ & $0.108 \pm 0.005$ & $0.123 \pm 0.004$ & $0.110 \pm 0.007$ & $F(3,31)=1.22, p=0.322$ \\
VRt & $0.641 \pm 0.012$ & $0.503 \pm 0.019^{*}$ & $0.635 \pm 0.017^{\dagger}$ & $0.620 \pm 0.014^{\dagger}$ & $F(3,31)=16.12, p<0.001$ \\
DGgcl & $0.071 \pm 0.007$ & $0.072 \pm 0.004$ & $0.075 \pm 0.004$ & $0.078 \pm 0.007$ & $F(3,31)=0.29, p=0.833$ \\
CAIpcl & $0.086 \pm 0.004$ & $0.087 \pm 0.006$ & $0.079 \pm 0.003$ & $0.078 \pm 0.005$ & $F(3,31)=0.91, p=0.449$ \\
CA2pcl & $0.098 \pm 0.006$ & $0.105 \pm 0.008$ & $0.105 \pm 0.005$ & $0.096 \pm 0.005$ & $F(3,31)=0.60, p=0.618$ \\
CA3pcl & $0.093 \pm 0.005$ & $0.078 \pm 0.004$ & $0.080 \pm 0.006$ & $0.068 \pm 0.005$ & $F(3,31)=2.37, p=0.120$ \\
\hline A & &
\end{tabular}

All data expressed as mean + SEM relative optical density (ROD, $N=8$ per treatment group). Vehicle is $3 \%$ glacial acetic acid in water. Animals were treated according to the chronic intermittent PCP treatment regime described within the Methods section. PCP dose is $2.58 \mathrm{mg} \mathrm{kg}^{-1}$; clozapine dose is $20 \mathrm{mg} \mathrm{kg}^{-1} \mathrm{day}^{-1}$ and haloperidol dose is $1 \mathrm{mg} \mathrm{kg}^{-1}$ day ${ }^{-1}$, with antipsychotics administered by osmotic minipump.

Significance was taken as $p<0.05$ (one-way ANOVA) after correction for multiple comparisons using the sequential Bonferroni correction method. $* 0<0.05$ (post hoc analysis) compared to vehicle-vehicle-treated animals. ${ }^{\dagger} p<0.05$ (post hoc analysis) compared to PCP-vehicletreated animals. $\# p<0.05$ (post hoc analysis) compared to PCP-haloperidol group. PrL, prelimbic cortex; ACg, anterior cingulate cortex; Aul, primary auditory cortex (layer I); AuD, dorsal nucleus of the secondary auditory cortex; vRt, reticular nucleus of thalamus; DGgcl, granule cell layer of dentate gyrus; CAIpcl, CA2pcl, CA3pcl, pyramidal cell layers of respective hippocampal fields. 


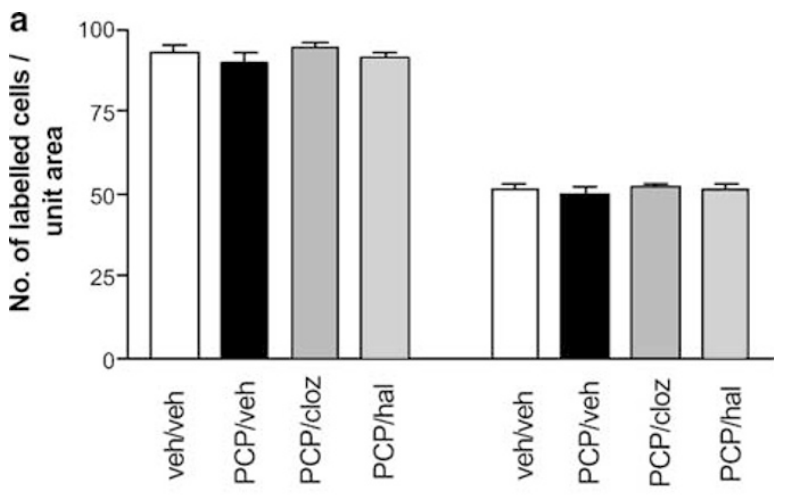

Layers I \&II Layers V\&VI

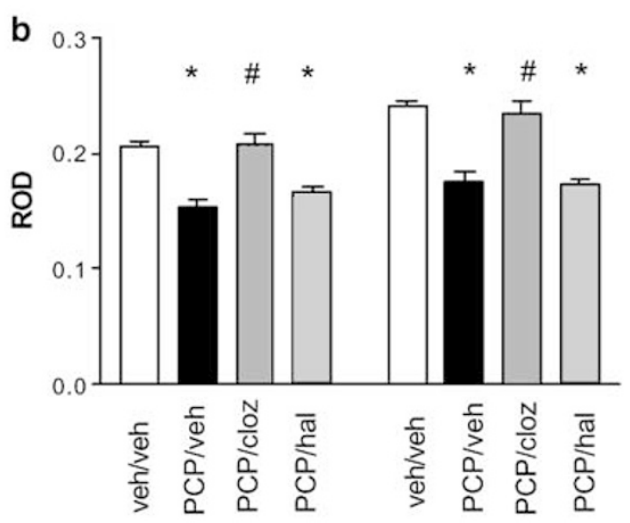

Layers I \&II

Layers V\&VI

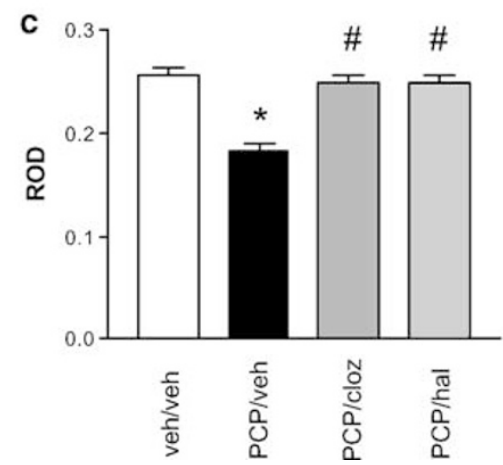

Figure 2 Cellular in situ hybridization signal for parvalbumin mRNA after PCP and antipsychotic drug treatment. (a) number of parvalbumin-labeled cells per unit area in the prelimbic cortex. (b) Density of cellular silver grains within the prelimbic cortex. (c) Density of cellular silver grains within the ventral reticular nucleus of the thalamus. Animals were treated according to the chronic intermittent PCP $\left(2.58 \mathrm{mg} \mathrm{kg}^{-1}\right.$ i.p.) treatment regime as described within the Methods section. Clozapine dose is $20 \mathrm{mg} \mathrm{kg}^{-1} \mathrm{day}^{-1}$ and haloperidol dose is $1 \mathrm{mg} \mathrm{kg}^{-1}$ day $^{-1}$, with antipsychotics administered by osmotic minipump. *signifies $p<0.05$ after application of the sequential Bonferroni correction factor compared to vehicle-vehicle-treated rats; \# signifies $p<0.05$ after correction with the sequential Bonferroni correction factor compared to PCP-vehicle-treated animals.

and within cortical and subcortical auditory structures. The chronic intermittent treatment regime used within this study therefore mimicked the 'hypofrontality' (decreased glucose utilization in the prefrontal cortex) that is observed after chronic PCP in drug abusers (Wu et al, 1991) and in schizophrenic patients (Wolkin et al, 1992; Andreasen et al, 1992; Tamminga et al, 1992).

In recent years, the use of NMDA receptor antagonists as a pharmacological model of schizophrenia has gained wide acceptance. However, it is evident that acute and chronic NMDA antagonist treatment produces different effects in some experimental paradigms and it has been suggested that repeated exposure to NMDA antagonists is a better model of schizophrenia, especially with regard to prefrontal cognitive dysfunction (reviewed by Jentsch and Roth, 1999). Acute and chronic exposure to NMDA antagonists produces opposing effects on glucose utilization. Acute treatment initially produces an increase in glucose utilization and uptake within the rodent prefrontal cortex (Miyamoto et al, 2000; Duncan et al, 1998; Gao et al, 1993), as well as increasing noradrenergic, serotonergic, dopaminergic and glutamatergic activity (Jentsch et al, 1997a, b; Hertel et al, 1996; Verma and Moghaddam, 1996; Deutch et al, 1987). Indeed, atypical antipsychotics, dopamine receptor antagonists, serotonin receptor antagonists and non-NMDA agonists have been shown to either blunten the increase in glucose metabolism associated with acute NMDA receptor antagonist treatment or attenuate other behavioral effects, such as sensory gating and hyperlocomotor activity (Miyamoto et al, 2001; Duncan et al, 2000, 1998; Yamada et al, 1999; Millan et al, 1999; Moghaddam and Adams, 1998). Interestingly, however, acute PCP treatment has been shown to elicit a dose-dependent biphasic response in glucose metabolism, where an increase in LCGU is observed up to $3 \mathrm{~h}$ after exposure, followed by a decrease in glucose metabolism which peaks at $24 \mathrm{~h}$ and returns to normal after $48 \mathrm{~h}$ (Gao et al, 1993). The mechanism underlying this biphasic response remains unknown. Within the prefrontal cortex, blockade of NMDA receptors has been shown to increase glutamate release (Adams and Moghaddam, 1998). This will lead to disinhibition of GABAergic interneurones, which in turn will lead to an increase in glutamate release, which explains the initial increase in glucose utilization or uptake, which will activate non-NMDA receptors. One explanation for this biphasic response is that the decrease in glucose metabolism is a protective compensatory corrective response to the hyperactivity of the glutamatergic system induced by NMDA receptor blockade. An alternative explanation is that the increased glutamate release sensitizes the non-NMDA receptors, which leads to a hypoactivity of the whole glutamatergic system that is then observed as a decrease in glucose utilization. This is supported by changes in zif 268 (an immediate early gene which is thought to represent glutamatergic activity) mRNA expression mirroring the same temporal profile as that induced by acute PCP (unpublished data) and MK801 (Gao et al, 1998).

The effects of subchronic NMDA antagonist administration in rats and primates have been shown to disrupt prefrontal cognitive function (Jentsch et al, 1997a,b). Chronic PCP abuse in humans has also been associated with cognitive deficits (Cosgrove and Newell, 1991). Neuropsychological evaluation prior to metabolic imaging of schizophrenic patients has provided the information that has enabled correlations to be made between areas displaying altered metabolic function and the nature of the symptomatology of individual patients. Decreased metabolic function within the prefrontal cortex has been 

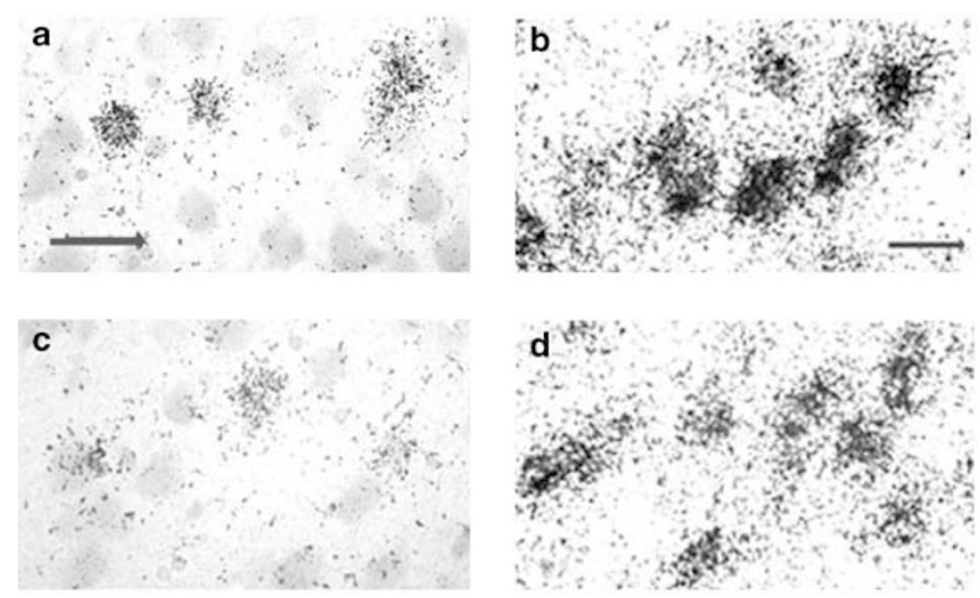

Figure 3 Representative silver-grain-labeled parvalbumin cells after chronic PCP treatment. Prefrontal cortex: (A) controls (vehicle-vehicle-treated animals); (C) PCP-vehicle; scale bar represents $20 \mu \mathrm{m}$. Reticular nucleus of the thalamus: (B) controls (vehicle-vehicle-treated animals); (D) PCP-vehicle; scale bar represents $25 \mu \mathrm{m}$. Animals were treated according to the chronic intermittent PCP $\left(2.58 \mathrm{mg} \mathrm{kg}{ }^{-1}\right.$ i.p.) treatment regime as described within the Methods section. Note the decreased intensity of silver grains in both structures after PCP treatment.

linked with the cognitive deficits and negative symptoms of schizophrenia. Although the antipsychotic clozapine has been shown to attenuate cognitive deficits (Jentsch et al, 1997a), we found that neither clozapine nor haloperidol could modulate the PCP-induced hypometabolism within the prelimbic cortex of the rat. The fact that the antipsychotics do not modulate the decreased metabolic activity induced by PCP in the prelimbic cortex is consistent with clinical data from imaging studies of schizophrenic patients, with metabolic hypofunction being observed in both medicated and nonmedicated patients (Hazlett et al, 2000; Cohen et al, 1997; Schroeder et al, 1994; Potkin et al, 1994; Buchsbaum et al, 1990, 1992). The inability of clozapine and haloperidol to attenuate this metabolic hypofunction within the prefrontal cortex is contrary to the ability of clozapine to attenuate the metabolic hyperfunction induced by acute NMDA receptor antagonist treatment (Duncan et al, 1998). This may mean that clozapine can only prevent the effects of PCP when it is administered prior to the psychotomimetic and not after the PCP-induced effects are established. This may reflect the fact that clozapine can block hyperactivity of the dopaminergic and serotonergic systems within the prefrontal cortex, which occurs after acute PCP administration, but cannot directly modulate hypoactivity of the glutamatergic system. Within subcortical auditory structures, such as the lateral lemniscus and the cochlear nucleus, chronic antipsychotic administration reversed the PCP-induced metabolic hypofunction. This is concordant with abnormal metabolic utilization in the temporal lobe and auditory nuclei being representative of positive symptoms such as hallucinations (Woodruff et al, 1997; David et al, 1996; Buchsbaum et al, 1990), which are effectively treated by typical and atypical antipsychotics.

This study also highlights that the effect of antipsychotics alone on glucose utilization does not predict whether the antipsychotics can reverse the PCP-induced deficits. Within the prelimbic cortex (layers I, V and VI), both clozapine and haloperidol significantly reduced glucose utilization but did not reverse the PCP-induced effect. Within the reticular nucleus of the thalamus, only chronic haloperidol produced a significant decrease in glucose utilization, but neither haloperidol nor clozapine reversed the PCP-induced hypometabolism. Chronic haloperidol also decreases glucose metabolism within the dorsal nucleus of the lateral lemniscus and cochlear nucleus, yet both chronic clozapine and haloperidol reversed the PCP-induced hypofunction within these structures. Further work is required to determine the mechanisms underlying these observations.

Further insight into the interaction between chronic intermittent PCP treatment combined with chronic antipsychotic treatment has been gained from parvalbumin mRNA expression with this treatment regime. The past decade has gone beyond the dopamine hypothesis and has led to the postulation that glutamatergic hypofunction and the subsequent disruption of the tonic influence of GABA may play a pivotal role in schizophrenia (Lewis, 2000; Olney et al, 1999; Tamminga, 1998). In particular, a certain subtype of GABAergic interneuron, chandelier cells, appears to be specifically affected in schizophrenia (Lewis et al, 1999; Pierri et al, 1999; Ohnuma et al, 1999). Furthermore, these chandelier cells also contain the calcium-binding protein parvalbumin (Conde et al, 1994), which has also been shown to be decreased in schizophrenic post-mortem tissue within the prefrontal cortex and the anterior thalamus (Beasley and Reynolds, 1997; Danos et al, 1998). This current study shows that chronic intermittent PCP administration also decreases parvalbumin mRNA expression in a structure-specific manner. Parvalbumin acts as a calcium buffer within the neuron, which acts to shorten the duration between action potentials, so facilitating the fast spiking phenotype and repetitive firing of short action potentials characteristic of this neuron. The decrease in parvalbumin mRNA expression is likely to reflect a downregulation of expression due to decreased activity of the GABAergic interneurons, which occurs as a result of NMDA channel blockade by PCP blocking the stimulatory effect of glutamate on GABA release. A downregulation of expression rather than PCP-induced cell loss is supported by the fact that the total number of cells exhibiting parvalbumin 
staining was not altered during chronic PCP treatment, but rather the density of staining within individual cells was decreased. Chandelier cells are in a prime position to modulate the excitability of the prefrontal cortex. Firstly, they synapse onto the axon initial segment of the pyramidal cell that allows powerful control over the excitability of these glutamatergic cells; secondly, dopaminergic efferents from the ventral tegmental area synapse onto the chandelier cells (Sesack et al, 1995, 1998) and lastly, these GABAergic cells are the primary targets for thalamocortical neurons (Melchitzky et al, 1999). Other studies have also demonstrated that parvalbumin-containing interneurons are fundamental in local circuits within the prefrontal cortex that are recruited in working memory (Rao et al, 1999) and that blockade of $\mathrm{GABA}_{\mathrm{A}}$ receptors also disrupts working memory (Sawaguchi et al, 1988). This, coupled with the fact that dopamine, which is also integral to normal working memory, has been shown to influence the expression and laminar distribution of parvalbumin within cortical cells in vitro, suggests that the decrease in parvalbumin observed in both schizophrenia and after chronic intermittent PCP treatment may be important in mediating the cognitive deficits and negative symptoms associated with schizophrenia.

Despite the fact that chronic clozapine and haloperidol do not modulate chronic intermittent PCP-induced hypometabolism within the prelimbic cortex and reticular nucleus of the rat, clozapine could reverse the decrease in parvalbumin mRNA expression within the prelimbic cortex, and clozapine and haloperidol reversed this neurochemical deficit within the reticular nucleus of the thalamus. This suggests that chronic antipsychotic treatment may normalize GABAergic activity, but cannot completely reverse hypofunction of the glutamatergic system. The reversal of parvalbumin mRNA expression appears to be due to a restoration of GABAergic function, as the density of staining within individual cells was returned to control levels after coadministration of antipsychotics. Whether the reversal of PCP-induced decreases in parvalbumin expression by clozapine and haloperidol is via the same mechanism within the thalamus but due to different mechanisms within the prefrontal cortex, remains to be determined. Within the prefrontal cortex, clozapine, but not haloperidol, has been shown to facilitate NMDA-receptor transmission (Arvanov et al, 1997) and also to decrease the functional hyperactivity of NMDA receptors in rats repeatedly exposed to PCP (Arvanov and Wang, 1999).

A delayed time point of measurement of metabolic function was adopted in the present study so that enduring, rather than acute effects of PCP could be investigated. We hypothesized and have shown that repeated exposure to PCP maintains the decrease in glucose utilization to produce an enduring metabolic hypofunction. Owing to the triphasic elimination of PCP (Misra et al, 1980) and the possibility of the extended presence of PCP in the brain, intermittent exposure was chosen so as to minimize the possible accumulation of the drug and the excitotoxic effects of PCP, which may be more pronounced after repeated exposure. There is a possibility that the hypometabolic state, which is induced by this chronic intermittent treatment with PCP, results from either sensitization to or withdrawal from PCP. Very few studies have investigated these effects in relation to PCP, although some groups have shown that repeated exposure to PCP produces a sensitization to the locomotor-stimulating effects of an acute PCP challenge. It may be expected that if the decrease in glucose utilization was a result of sensitization, the effects of chronic intermittent exposure to PCP would produce a more pronounced metabolic hypofunction than that observed after subchronic treatment. However, this was not observed in these studies. Furthermore, if sensitization occurred, it might be expected that exposure to higher and more frequent doses of PCP would also produce a metabolic hypofunction. However, when we measured glucose utilization after treatment with $5 \mathrm{mg} / \mathrm{kg}$ PCP twice daily for 7 days (glucose utilization measured $72 \mathrm{~h}$ after the last exposure to PCP), no hypometabolic state was observed in any brain structure (data not shown). Thus, it is possible that the hypometabolic state observed after chronic intermittent exposure to PCP according to our treatment regime is not directly related to withdrawal period or sensitization to the effects of PCP, although further work is required to clarify this.

In summary, this is the first time that the effect of chronic intermittent PCP treatment on functional activity has been described. The results demonstrate that, under the treatment protocol reported here, the metabolic hypofunction, and also some of the neurochemical abnormalities, induced by chronic intermittent PCP exposure mirrors those observed in schizophrenia. In addition, chronic coadministration of antipsychotics differentially reverses PCP-induced decreases in parvalbumin mRNA expression. These data provide new evidence which substantiates the use of chronic PCP administration as a model of schizophrenia, and suggest that altered parvalbumin expression may be a potential marker of atypical antipsychotic activity related to amelioration of cognitive deficits and negative symptoms in schizophrenia.

\section{ACKNOWLEDGMENTS}

We would like to thank Mr Allan McVie for his technical assistance within these studies. We would also like to thank Prof AL Harvey, Dr R Hunter, Dr MG Livingston, Prof TW Stone, Dr CMR Turner and Dr H Yasamatsu of the YRING Research Management Team for their helpful comments on the work and in the preparation of this manuscript.

\section{REFERENCES}

Adams B, Moghaddam B (1998). Corticolimbic dopamine neurotransmission is temporally dissociated from the cognitive and locomotor effects of phencyclidine. J Neurosci 18: 5545-5554.

Allen RM, Young SJ (1978). Phencyclidine-induced psychosis. Am J Psychiatry 135: 1081-1084.

Andreasen NC, Rezai K, Alliger R, Swayze VW, Flaum M, Kirchner $P$ et al (1992). Hypofrontality in neuroleptic-naive patients and in patients with chronic schizophrenia. Assessment with xenon 133 single-photon emission computed tomography and the Tower of London. Arch Gen Psychiatry 49: 943-958.

Arvanov VL, Liang X, Schwartz J, Grossman S, Wang RY (1997). Clozapine and haloperidol modulate $N$-methyl-D-aspartate- and non- $N$-methyl-D-aspartate receptor-mediated neurotransmis- 
sion in rat prefrontal cortical neurons in vitro. J Pharmacol Exp Ther 283: 226-234.

Arvanov VL, Wang RY (1999). Clozapine, but not haloperidol, prevents the functional hyperactivity of $\mathrm{N}$-methyl-D-aspartate receptors in rat cortical neurons induced by subchronic administration of phencyclidine. J Pharmacol Exp Ther 289: 1000-1006.

Beasley CL, Reynolds GP (1997). Parvalbumin-immunoreactive neurons are reduced in the prefrontal cortex of schizophrenics. Schizophr Res 24: 349-355.

Buchsbaum MS, Hazlett EA (1998). Positron emission tomography studies of abnormal glucose metabolism in schizophrenia. Schizophr Bull 24: 343-364.

Buchsbaum MS, Nuechterlein KH, Haier RJ, Wu J, Sicotte N, Hazlett E et al (1990). Glucose metabolic rate in normals and schizophrenics during the Continuous Performance Test assessed by positron emission tomography. $\mathrm{Br} J$ Psychiatry 156: 216-227.

Buchsbaum MS, Potkin SG, Marshall JF, Lottenberg S, Teng C, Heh CW et al (1992). Effects of clozapine and thiothixene on glucose metabolic rate in schizophrenia. Neuropsychopharmacology 6: 155-163.

Buchsbaum MS, Someya T, Teng CY, Abel L, Chin S, Najafi A et al (1996). PET and MRI of the thalamus in never-medicated patients with schizophrenia. Am J Psychiatry 153: 191-199.

Cohen RM, Nordahl TE, Semple WE, Andreason P, Litman RE, Pickar D (1997). The brain metabolic patterns of clozapineand fluphenazine-treated patients with schizophrenia during a continuous performance task. Arch Gen Psychiatry 54: 481-486.

Conde F, Lund JS, Jacobowitz DM, Baimbridge KG, Lewis DA (1994). Local circuit neurons immunoreactive for calretinin, calbindin D-28k or parvalbumin in monkey prefrontal cortex: distribution and morphology. J Comp Neurol 341: 95-116.

Cosgrove J, Newell TG (1991). Recovery of neuropsychological functions during reduction in use of phencyclidine. J Clin Psychol 47: 159-169.

Crane AM, Porrino LJ (1989). Adaptation of the quantitative $2-\left[{ }^{14} \mathrm{C}\right]$ deoxyglucose method for use in freely moving rats. Brain Res 499: 87-92.

Danos P, Baumann B, Bernstein HG, Franz M, Stauch R, Northoff $G$ et al (1998). Schizophrenia and anteroventral thalamic nucleus: selective decrease of parvalbumin-immunoreactive thalamocortical projection neurons. Psychiatry Res 82: 1-10.

David AS, Woodruff PW, Howard R, Mellers JD, Brammer M, Bullmore E et al (1996). Auditory hallucinations inhibit exogenous activation of auditory association cortex. Neuroreport 7: $932-936$

Deutch AY, Tam SY, Freeman AS, Bowers Jr MB, Roth RH (1987). Mesolimbic and mesocortical dopamine activation induced by phencyclidine: contrasting response to striatal response. Eur J Pharmacol 134: 257-264.

Duncan GE, Leipzig JN, Mailman RB, Lieberman JA (1998). Differential effects of clozapine and haloperidol on ketamineinduced brain metabolic activation. Brain Res 812: 65-75.

Duncan GE, Miyamoto S, Leipzig JN, Lieberman JA (2000). Comparison of the effects of clozapine, risperidone, and olanzapine on ketamine-induced alterations in regional brain metabolism. J Pharmacol Exp Ther 293: 8-14.

Farber NB, Wozniak DF, Price MT, Labruyere J, Huss J, St Peter H et al (1995). Age-specific neurotoxicity in the rat associated with NMDA receptor blockade: potential relevance to schizophrenia?Biol Psychiatry 38: 788-796.

Freed WJ (1988). The therapeutic latency of neuroleptic drugs and nonspecific postjunctional supersensitivity. Schizophr Bull 14: 269-277.

Gao X-M, Hashimoto T, Tamminga CA (1998). Phencyclidine (PCP) and dizocilpine (MK801) exert time-dependent effects on the expression of immediate early genes in rat brain. Synapse 29: $14-28$.

Gao X-M, Shirakawa O, Du F, Tamminga CA (1993). Delayed regional metabolic actions of phencyclidine. Eur. J Pharmacol 241: 7-15.

Hazlett EA, Buchsbaum MS, Jeu LA, Nenadic I, Fleischman MB, Shihabuddin L et al (2000). Hypofrontality in unmedicated schizophrenia patients studied with PET during performance of a serial verbal learning task. Schizophr Res 43: 33-46.

Hertel P, Mathe JM, Nomikos GG, Iurlo M, Mathe AA, Svensson TH (1996). Effects of d-amphetamine and phencyclidine on behaviour and extracellular concentrations of neurotensin and dopamine in the ventral striatum and medial prefrontal cortex of the rat. Behav Brain Res 72: 103-114.

Javitt DC, Zukin SR (1991). Recent advances in the phencyclidine model of schizophrenia. AM J Psychiatry 148: 1301-1308.

Jentsch JD, Redmond DE, Elsworth JD, Taylor JR, Youngren KD, Roth RH (1997a). Enduring cognitive deficits and cortical dopamine dysfunction in monkeys after long-term administration of phencyclidine. Science 277: 953-955.

Jentsch JD, Roth RH (1999). The Neuropsychopharmacology of Phencyclidine: from NMDA receptor hypofunction to the dopamine hypothesis of schizophrenia. Neuropsychopharmacology 20: 201-225.

Jentsch JD, Tran A, Le D, Youngren KD, Roth RH (1997b). Subchronic phencyclidine administration reduces mesoprefrontal dopamine utilization and impairs prefrontal corticaldependent cognition in the rat. Neuropsychopharmacology 17: 92-99.

Kesner RP, Dakis M (1997). Intrahippocampal injections of phencyclidine but not naloxone disrupt acquisition of a spatial continuous recognition memory task. Pharmacol Biochem Behav 56: $97-101$.

Krystal JH, Karper LP, Seibyl JP, Freeman GK, Delaney R, Bremner JD et al (1994). Subanesthetic effects of the noncompetitive NMDA antagonist, ketamine, in humans. Psychotomimetic, perceptual, cognitive, and neuroendocrine responses. Arch Gen Psychiatry 51: 199-214.

Lewis DA (2000). GABAergic local circuit neurons and prefrontal cortical dysfunction in schizophrenia. Brain Res Brain Res Rev 31: 270-276.

Lewis DA, Pierri JN, Volk DW, Melchitzky DS, Woo TU (1999). Altered GABA neurotransmission and prefrontal cortical dysfunction in schizophrenia. Biol Psychiatry 46: 616-626.

Luby ED, Cohen CB, Rosenbaum G, Gottlieb JS, Kelly R (1959). Study of a new schizophrenomimetic drug - Serynl. Arch Neurol Psychiatry 81: 363-369.

Mansbach RS, Geyer MA (1989). Effects of phencyclidine and phencyclidine biologs on sensorimotor gating in the rat. Neuropsychopharmacology 2: 299-308.

Melchitzky DS, Sesack SR, Lewis DA (1999). Parvalbuminimmunoreactive axon terminals in macaque monkey and human prefrontal cortex: laminar, structureal, and target specificity of type I and type II synapses. J Comp Neurol 408: 11-21.

Millan MJ, Brocco M, Gobert A, Joly F, bervoets K, Rivet J et al (1999). Contrasting mechanisms of action and sensitivity to antipsychotics of phencyclidine $v s$ amphetamine: importance of nucleus accumbens 5HT2A sites for PCP-induced locomotion in the rat. Eur J Neurosci 11: 4419-4432.

Misra AL, Pontani RB, Bartolomeo JG (1980). Disposition of $\left[{ }^{3} \mathrm{H}\right]$ phencyclidine in the rat after single and multiple doses. Life Sci 27: 2501-2508.

Miyamoto S, Mailman RB, Lieberman JA, Duncan GE (2001). Blunted brain metabolic response to ketamine in mice lacking $\mathrm{D}$ (1A) dopamine receptors. Brain Res 894: 167-180.

Miyamoto S, Leipzig JN, Lieberman JA, Duncan GE (2000). Effects of ketamine, MK-801, and amphetamine on regional brain 2deoxyglucose uptake in freely moving mice. Neuropsychopharmacology 22: 400-412. 
Moghaddam B, Adams BW (1998). Reversal of phencyclidine effects by a group II metabotropic glutamate receptor agonist in rats. Science 281: 1349-1352.

Nordahl TE, Kusubov N, Carter C, Salamat S, Cummings AM, O'Shora-Celaya L et al (1996). Temporal lobe metabolic differences in medication-free outpatients with schizophrenia via the PET-600. Neuropsychopharmacology 15: 541-554.

Ohnuma T, Augood SJ, Arai H, McKenna PJ, Emson PC (1999). Measurement of GABAergic parameters in the prefrontal cortex in schizophrenia: focus on GABA content, GABA(A) receptor alpha-1 subunit messenger RNA and human GABA transporter-1 (HGAT-1) messenger RNA expression. Neuroscience 93: 441-448.

Olney JW, Labrugere J, Price MT (1989). Pathological changes induced in cerebrocortical neurons by phancydictive and related drugs. Science 244: 1360-1362.

Olney JW, Farber NB (1995). Glutamate receptor dysfunction and schizophrenia. Arch Gen Psychiatry 52: 998-1007.

Olney JW, Newcomer JW, Farber NB (1999). NMDA receptor hypofunction model of schizophrenia. J Psychiatr Res 33: 523-533.

Ongur D, Price JL (2000). The organisation of networks within the orbital and medial preforntal cortex of rats, monkeys \& humans. Cereb Cortex 10: 206-219.

Paxinos G (1995). The Rat Nervous System. 2nd edn. Academic Press: Sydney.

Paxinos G, Watson C (1998). The Rat Brain in Stereotaxic Coordinates. 4th edn. Academic Press: Sydney.

Phelps ME, Huang SC, Hoffman EJ, Selin C, Sokoloff L, Kuhl DE (1979). Tomographic measurement of local cerebral glucose metabolic rate in humans with (F-18)2-fluoro-2-deoxy-D-glucose: validation of method. Ann Neurol 6: 371-388.

Pierri JN, Chaudry AS, Woo TU, Lewis DA (1999). Alterations in chandelier neuron axon terminals in the prefrontal cortex of schizophrenic subjects. Am J Psychiatry 156: 1709-1719.

Potkin SG, Buchsbaum MS, Jin Y, Tang C, Telford J, Friedman G et al (1994). Clozapine effects on glucose metabolic rate in striatum and frontal cortex. J Clin Psychiatry 55(Suppl B): 63-66.

Rao SG, Williams GV, Goldman-Rakic PS (1999). Isodirectional tuning of adjacent interneurons and pyramidal cells during working memory: evidence for microcolumnar organization in PFC. J Neurophysiol 81: 1903-1916.

Reich DL, Silvay G (1989). Ketamine: an update on the first twentyfive years of clinical experience. Can J Anaesth 36: 186-197.

Sams-Dodd F (1997). Effect of novel antipsychotic drugs on phencyclidine-induced stereotyped behaviour and social isolation in the rat social interaction test. Behav Pharmacol 8: 196-215.

Sawaguchi T, Matsumura M, Kubota K (1988). Delayed response deficits in monkeys by locally disturbed prefrontal neuronal activity by bicuculline. Behav Brain Res 31: 193-198.

Schroeder J, Buchsbaum MS, Siegel BV, Geider FJ, Haier RJ, Lohr J et al (1994). Patterns of cortical activity in schizophrenia. Psychol Med 24: 947-955.
Schroder J, Buchsbaum MS, Siegel BV, Geider FJ, Lohr J, Tang C et al (1996). Cerebral metabolic activity correlates of subsyndromes in chronic schizophrenia. Schizophr Res 19: 41-53.

Sesack SR, Hawrylak VA, Melchitzky DS, Lewis DA (1998). Dopamine innervation of a subclass of local circuit neurons in monkey prefrontal cortex: ultrastructural analysis of tyrosine hydroxylase and parvalbumin immunoreactive structures. Cereb Cortex 8: 614-622.

Sesack SR, Snyder CL, Lewis DA (1995). Axon terminals immunolabeled for dopamine or tyrosine hydroxylase synapse on GABA-immunoreactive dendrites in rat and monkey cortex. $J$ Comp Neurol 363: 264-280.

Sokoloff L, Reivich M, Kennedy C, Des-Rosiers MH, Patlak CS, Pettigrew KD et al (1977). The $\left[{ }^{14} \mathrm{C}\right]$ deoxyglucose method for the measurement of local cerebral glucose utilization: theory, procedure, and normal values in the conscious and anesthetized albino rat. J Neurochem 28: 897-916.

Tamminga CA (1998). Schizophrenia and glutamatergic transmission. Crit Rev Neurobiol 12: 21-36.

Tamminga CA, Thaker GK, Buchanan R, Kirkpatrick B, Alphs LD, Chase TN et al (1992). Limbic system abnormalities identified in schizophrenia using positron emission tomography with fluorodeoxyglucose and neocortical alterations with deficit syndrome. Arch Gen Psychiatry 49: 522-530.

Uylings HBM, Van Eden CG (1990). Qualitative and quantitative comparison of the prefrontal cortex in rats and in primates, including humans. Progr Brain Res 85: 31-62.

Verma A, Moghaddam B (1996). The role of excitatory amino acids in prefrontal cortex function as assessed by spatial delayed alternation performance in rats: modulation by dopamine. $J$ Neurosci 16: 373-379.

Volz H, Gaser C, Hager F, Rzanny R, Ponisch J, Mentzel H et al (1999). Decreased frontal activation in schizophrenics during stimulation with the continuous performance test: a functional magnetic resonance imaging study. Eur Psychiat 14: 17-24.

Wolkin A, Sanfilipo M, Wolf AP, Angrist B, Brodie JD, Rotrosen J (1992). Negative symptoms and hypofrontality in chronic schizophrenia. Arch Gen Psychiatry 49: 959-965.

Woodruff PW, Wright IC, Bullmore ET, Brammer M, Howard RJ, Williams SC et al (1997). Auditory hallucinations and the temporal cortical response to speech in schizophrenia: a functional magnetic resonance imaging study. Am J Psychiatry 154: $1676-1682$

Wu JC, Buchsbaum MS, Bunney WE (1991). Positron emission tomography study of phencyclidine users as a possible drug model of schizophrenia. Yakubutsu Seishin Kodo 11: 47-48.

Yamada S, Harano M, Annoh N, Nakamura K, Tanaka M (1999). Involvement of serotonin $2 \mathrm{~A}$ receptors in phencyclidine-induced disruption of prepulse inhibition of the acoustic startle response. Biol Psychiatry 15: 832-838. 